multiforme ${ }^{18}$ or Ehlers-Danlos syndrome. ${ }^{19}$ Nevertheless, such diagnostic problems rarely present much difficulty. More often the crux of the matter is to decide whether demonstrable trauma was caused by accident or not. Inevitably mistakes will be made in both directions. The case conference with all relevant professional workers, including doctors, nurses, social workers, health visitors, nursery staff, and often police, is aimed at serving the best interests of the child, sharing the burden of professional responsibility, and trying to minimise the scope for error; but where serious doubt remains after full consultation and there is concern for the safety of the child the ultimate arbiter must be society as a whole as represented in a court of law.

Child abuse has a twofold relation with cerebral palsy: brain damage may be the consequence or the precursor of inflicted injury. Among 86 children with cerebral palsy attending one centre in a deprived area of Chicago there were eight whose brain damage resulted from abuse and eight who were abused after the diagnosis of cerebral palsy was made. ${ }^{20}$ A further 12 were thought to be at serious risk of abuse. Such figures cannot be taken to be representative. In Liverpool physical abuse appeared to be much less common both before and after the diagnosis of cerebral palsy, ${ }^{21}$ but paediatricians should try to practise prevention by providing help which is readily available when needed for the parents of young children. ${ }^{22}$

The outcome for children who have been seriously abused is often poor. In a socially deprived inner city area of Liverpool 50 children were taken into the care of the local authority after being abused. Twenty five of them were later returned to their parents, and the outcome was considered satisfactory in seven. ${ }^{23}$ Five suffered further abuse. In the 25 who were not returned to their parents the outcome was thought to be satisfactory in 17. Factors tending to an unsatisfactory outcome were increasing age when first taken into care, increasing length of time in care before returning to the parents, and multiple placements while in care. The children who did best were those for whom an early decision was made to sever contact with the parents and to place the child with a substitute family.

No controls were used in the Liverpool study, but an Australian study compared the personality development of abused children with that of controls matched for age, sex, ethnic group, and social class. ${ }^{24}$ When examined several years after the abuse the study children were found to have fewer friends, less ambition, lower self esteem, and more behaviour disturbance than the controls. The personality traits of abused children justify concern about their development of parenting skills when they reach adulthood-and the likely repetition of the cycle of deprivation and abuse. Professional intervention must be aimed at breaking this cycle.

D P ADDY

Consultant Paediatrician,

Dudley Road Hospital,

Birmingham B18 7QH

\footnotetext{
1 Select Committee on Violence in the Family. Violence to children. First report. Session 1976-7. London: HMSO, 1977.

2 Oliver JE. Dead children from problem families in NE Wiltshire. Br Med $\mathcal{J}$ 1983;286:115-7.

3 Lynch M, Roberts J. Predicting child abuse: signs of bonding failure in the maternity hospital. $\mathrm{Br}$ Med J 1977; i:624-6.

4 Lealman GT, Haigh D, Philips JM, Stone J, Ord-Smith C. Prediction and prevention of child abuse-an empty hope? Lancet 1983;i:1423-4.

5 Jenkins J, Gray OP. Changing clinical picture of non-accidental injury to children. $\mathrm{Br} M e d \mathcal{F}$ 1983;287:1767-9.

6 Hobbs CJ. Skull fracture and the diagnosis of abuse. Arch Dis Child 1984;59:246-52.

7 Feddman KW, Brewer DK. Child abuse, cardiopulmonary resuscitation and rib fractures. Pediatrics 1984;73:339-42.

8 Roberton DM, Barbor P, Hull D. Unusual injury? Recent injury in normal children and children with suspected non-eccidental injury. $B r$ Med $\mathcal{F}$ 1982;285:1399-401.
}

9 Grant LJ. Assessment of child sexual abuse: eighteen months' experience at the Child Protection w Center. Am J Obstet Gynecol 1984;148:617-20.

10 Khan M, Sexton M. Sexual abuse of young children. Clin Pediatr (Phila) 1983;22:369-72. 11 Furniss T, Bingley-Miller L, Bentovim A. Therapeutic approach to sexual abuse. Arch Dis Child
1984;59:865-70.

12 Gardiner $M$, Jones JG. Genital herpes acquired by sexual abuse of children. $\mathcal{J}$ Pediatr 1984;104:243-4.

13 Meadow R. Munchausen syndrome by proxy. Arch Dis Child 1982;57:92-8.

14 Meadow R. Fictitious epilepsy. Lancet 1984;ii:25-8.

15 Warner JO, Hathaway MJ. Allergic form of Meadow's syndrome (Munchausen by proxy). Arch Dis Child 1984;59:151-6.

16 O'Hare AE, Eden OB. Bleeding disorders and non-accidental injury. Arch Dis Child 1984;59: 860-4.

17 Oates RK. Overturning the diagnosis of child abuse. Arch Dis Child 1984;59:665-6.

18 Adler R, Kane-Nussen B. Erythema multiforme: confusion with child battering syndrome. Pediatrics 1983;72:718-20.

19 Owen SM, Durst RD. Ehlers-Danlos syndrome simulating child abuse. Arch Dermatol 1984;120: 97-101.

20 Diamond LJ, Jaudes PK. Child abuse in a cerebral-palsied population. Dev Med Child Neuro 1983;25:169-74.

21 Hensey O, llett SJ, Rosenbloom L. Child abuse and cerebral palsy. Lancet 1983;ii:400.

22 Bax M. Child abuse and cerebral palsy. Deo Med Child Neurol 1983;25:141-2.

23 Hensey OJ, Williams JK, Rosenbloom L. Intervention in child abuse: experience in Liverpool. Deo Med Child Neurol 1983;25:606-11.

24 Oates RK. Personality development after physical abuse. Arch Dis Child 1984;59:147-50

\section{Ketoconazole: a reappraisal}

The recent letter from the chairman of the Committee on the Safety of Medicines to doctors in Britain about oral ketoconazole and hepatotoxicity has aroused widespread concern. This imidazole antifungal drug is available for both oral and topical use and so has wide potential clinical applications. Serious adverse effects have been rare, though symptoms such as gynaecomastia related to androgen blocking activity ${ }^{1}$ and anaphylaxis have been reported in addition to hepatotoxicity. ${ }^{2}$ The effect of ketoconazole on the liver ranges from asymptomatic transient abnormalities of the enzyme activities to potentially fatal acute hepatic necrosis. ${ }^{3}$ In view of these findings clearly the risks of using the drug need to be weighed against the likely benefits to the patient. Fortunately, considerably more information is now available on the clinical uses of ketoconazole than when it was first reviewed in the $B M$ F. $^{4}$

Many superficial fungal infections are best treated with topically applied antifungal agents. In dermatophytosis (ringworm) oral treatment should be reserved for infections of the scalp or nails and for widespread disease. Though ketoconazole is effective in dermatophytosis, comparative studies have shown that it has no real clinical advantages over griseofulvin ${ }^{5}$ except in some specific or resistant cases such as intractable tinea corporis. ${ }^{6}$ In particular, both drugs produce similar responses in nail infections (which are notoriously difficult to treat). ${ }^{7}$ Ketoconazole may be effective in some fingernail infections which have failed to respond to adequate treatment with griseofulvin.

In the second main group of superficial infections, candidiasis, topical antifungals are also generally effective. In vaginal candidiasis, for instance, one large study found no difference in response rates to topical clotrimazole and oral ketoconazole, though patients preferred the latter. ${ }^{8}$ In persistent and distressing superficial candidal infections, however, and in particular in chronic mucocutaneous candidiasis 9 ketoconazole appears to offer the best chance of clinical recovery. Generally the alternative drugs are satisfactory for the superficial fungal infections, and ketoconazole may be reserved for specific indications.

Deep fungal infections present different problems in view of the risk of severe incapacity or even death in untreated patients. Ketoconazole is effective in the tropical sub- 
cutaneous mycoses such as mycetoma due to Madurella mycetomatis ${ }^{10}$ and conidiobolomycosis. "It is also particularly useful for certain systemic fungal infections, including all cases of paracoccidioidomycosis, ${ }^{12}$ and localised disseminated forms of histoplasmosis, ${ }^{13}$ blastomycosis, ${ }^{14}$ and coccidioidomycosis. ${ }^{13}$ Assessing the clinical response to treatment in systemic opportunistic fungal infections is often difficult, so that the evidence that ketoconazole is effective in these disorders is not complete. Some specific uses have been reported, however, such as for localised deep candidal infections in patients with acquired immune deficiency syndrome ${ }^{15}$ and systemic candidiasis in heroin addicts. "In patients who are seriously immunocompromised oral antifungal prophylaxis remains a logical approach even though there are few studies confirming its value in preventing systemic infection. Ketoconazole is effective as a prophylactic, and in some studies it appears to have been superior to alternatives such as nystatin, ${ }^{16}$ although the emergence of carriage of other potentially pathogenic yeasts such as Candida (Torulopsis) glabrata in treated patients may be another factor that has to be taken into account.

So long as ketoconazole is reserved for specific indications use may be made of its distinctive features without exposing patients to an unnecessary hazard, however rare. Ketoconazole also remains an alternative method of antifungal treatment where other drugs cannot be used, each case being carefully considered on its individual merits. Patients receiving the drug should be told to report the specific side effects and both their clinical state and their liver function values should be monitored. A recent analysis of 33 cases of symptomatic hepatic injury due to ketoconazole reported in the United States estimated the incidence at roughly one in 15000 exposed patients, and showed that liver damage might occur at any time between 11 and 168 days of treatment, was commoner in women over 40, and was not necessarily associated with high doses. Clinicians should continue to report as many data as possible on the adverse effects of ketoconazole as this information is essential for all using the drug.

\section{RODERICK J HaY}

Senior Lecturer in Clinical Mycology,

London School of Hygiene and Tropical Medicine,

London WC1E 7HT 1 De Felici R, Johnson DG, Galgiani JM. Gynecomastia with ketoconazole. Antimicrob Agents
Chemother 1981;19:1073-4.

2 Heiberg JK, Svejgard E. Toxic hepatitis during ketoconazole treatment. Br Med $\mathcal{F} 1981 ; 283$ : 825-6.

3 Lewis JH, Zimmerman JH, Benson GD, Ishak KG. Hepatic injury associated with ketoconazole therapy-an analysis of 33 cases. Gastroenterology 1984;86:503-13.

4 Hay R. Ketoconazole. Br Med J 1982;285:584-5.

5 Robertson MH, Rich P, Parker F, Hanifin JM. Robertson MH, Rich P, Parker F, Hanifin JM.
dermatophytosis. 3 Am Acad Dermatol 1982;6:224-32.

dermatophytosis. $\mathcal{F}$ Am Acad Dermatol 1982;6:224-32. Stratigos I, Zissis NP, Katsambas A, et al. Ketoconazole compared with griseofulvin in dermatophytoses: a randomised double-blind trial. Dermatologica 1983; 166:161-4.

7 Zaias N, Drachman D. A method for the determination of drug effectiveness in onychomycosis. $f$ Am Acad Dermatol 1983;9:912-5.

8 Bingham JS. Single blind comparison of ketoconazole $200 \mathrm{n}$ s oral tablets and clotrimazole $100 \mathrm{mg}$ vaginal tablets and $1 \%$ cream in treating acute vaginal canu:dosis. Br $\mathcal{G}$ Vener Dis 1984;60:175-7.

9 Hay RJ, Clayton YM. The treatment of patients with chronic mucocutaneous candidosis and candida onychomycosis with ketoconazole. Clin Exp Dermatol 1982;7:155-62.

10 Mahgoub ES, Gumaa SA. Ketoconazole in the treatment of eumycetoma due to Madurella mycetomii. Trans R Soc Trop Med Hyg 1984;7:376-9.

1 Drouhet E, Dupont B. Laboratory and clinical assessment of ketoconazole in deep-seated mycoses. Am J Med 1983;74(1B):30-47.

12 Restrepo A, Stevens DA, Gomez I, et al. Ketoconazole, a new drug for the treatment of paracoccidioidomycosis. Reo Infect Dis 1980;2: 633-42.

13 Dismukes WE, Stamm AM, Graybill JR, et al. Treatment of systemic mycoses with ketoconazole: emphasis on toxicity and clinical response in 52 patients. Ann Intem Med 1983;98:13-20.

14 Hudson CP, Allen JP. Systemic blastomycosis treated with ketoconazole. Arch Dermatol 1984;120:536-8.

15 Gottlieb MS, Schroff R, Schonker HM, et al. Pneumocystis carinii pneumonia and mucosal candidiasis in previously healthy homosexual men. Evidence of a new acquired cellular immunodeficiency. N Engl I Med 1981;305:1425-31.

16 Hann IM, Prentice HG, Corringham R, et al. Ketoconazole versus nystatin plus amphotericin B for fungal prophylaxis in severely immunocompromised patients. Lancet 1982;i:826-9.

\section{Risk of leukaemia associated with cancer chemotherapy}

The objectives of the treatment of cancer must be to restore a good quality of life and when possible cure. The experienced clinician should be able to weigh the risks of temporary morbidity associated with a particular treatment against the prospect of achieving these objectives. As the results of treatment improve and survival is prolonged new clinical events may become manifest in association either with the disease or with its treatment. When this happens the late effects of treatment must be distinguished from those of the disease itself.

Potentially one of the most serious late events is the induction of a second cancer. An association between the administration of arsenic and the development of squamous cell carcinoma was recognised a century ago, and in the late 1940 s an antineoplastic drug was shown to have carcinogenic properties. ${ }^{1}$ Of the various classes of anticancer drugs the alkylating agents, which so effectively damage DNA, might be expected to induce malignant change in a predictable fashion. Proving this suspicion conclusively and in a way that might usefully modify clinical practice has been a difficult and lengthy exercise. Plainly the problem is not substantial, for despite the widespread use of chemotherapy second cancers are rare (though this may partly reflect the limited survival of many of those treated). When second malignancies do occur the epidemiologist might reasonably argue that these may be spontaneous in patients with an increased tendency to malignant change. Both features might be expected to be more apparent in patients whose survival is increased. At present measurement of the risk of malignancy induced by treatment depends on the relation between the observed number of cases and those which might be expected for the population studied. Identifying this denominator is a weak link in the calculation but one that may be strengthened by comparing different types of populations theoretically at risk.

Exposure to radiation might be regarded as the benchmark for comparison. The Japanese populations exposed to whole body irradiation from the atomic bombs showed an increase in acute non-lymphoblastic leukaemia after some years and in solid tumours after a much longer latent period. For this type of exposure a dose relation may be identified, whereas that resulting from high dose fractionated irradiation is much more haphazard. The relation between exposure to radiation and the induction of cancer is highly complex, so that comparisons with exposure to radiation may not be appropriate or helpful in understanding the risks of leukaemia induced by chemotherapy. ${ }^{2}$

The mechanism of induction of malignant change is almost certainly unrelated to immunosuppression even though the incidence of some types of malignant tumours does increase in patients who are immunosuppressed (by whatever means). ${ }^{3}$ Acute non-lymphoblastic leukaemia features only rarely among the resulting tumours.

Retrospective analyses of patients with cancer who have received different permutations of treatments indicate that in some groups the incidence of acute non-lymphoblastic leukaemia seems to be increased above that expected. The problems of relating this to treatment should not be underestimated, but a certain consistency in outcome is apparent among the surveys from different centres. An increased incidence (observed over expected) has been seen in patients 